\title{
Application of BIM technology in operation of port marine structures
}

\author{
Pavel Garibin ${ }^{1}$, and Evgeniy Ol'khovik ${ }^{1, *}$ \\ ${ }^{1}$ Admiral Makarov State University of Maritime and Inland Shipping, Dvinskaya 5/7, St. \\ Petersburg, 198035, Russia
}

\begin{abstract}
The features of the BIM model development for marine port facilities operation are discussed. Infrastructure objects differ significantly from linear and area objects, the use of information modeling for transport infrastructure requires a new approach to organization of design, construction and especially for operation. Most seaports were built long ago and there is not to have the project documentation for them. It is therefore very relevant is the problem of adapting existing building and design documentation to develop models of operation. Infrastructure projects always have a large number of interconnections that are irregular and difficult to formalize into an information model. Port berthing facilities in an intensive mode interact with the courts, a water space, the cargo base and special cargo handling equipment. On the example of the design model of the seaport, we collected sufficient data for their further integration into the BIM model and the transfer of information in digital form for its repeated use at different stages of the life cycle of the seaport. The individual information schemes and elements for standardization of the design of offshore mooring structures, taking into account of turnover in objectoriented format with attribute data are offered. The model includes the necessary information on all parameters of operation of the berthing facility, planning of measures for emergency situations, standard calendar work plan, schedules for monitoring the technical condition, financial estimates for operational maintenance, repairs, etc. The activities on the automation of deformation monitoring system, calculation of structural strength of the main structural elements and control risks are additionally proposed. The transition to life-cycle contracts in the operation of marine berthing facilities is justified.
\end{abstract}

\section{Introduction}

Information modeling (BIM) technologies in civil and industrial construction are actively developing. The objects of maritime transport infrastructure are very different from linear

\footnotetext{
*Corresponding author: olhovikeo@gumrf.ru
} 
and area square building objects. Seaport berthing facilities have even more differences, therefore in that paper we will try to consider some issues of BIM-technologies using for the operation and design of marine ports structures. Continuous interaction of the vessel with the port water area, berths and handling equipment in vulnerable environment conditions of the overwater and underwater parts of the structure is a durability process, the information description of which is very strong and difficult. Currently, most port building structures and transport infrastructure facilities have a traditional 2D description, less often3D performance, this allows engineers to solve only individual solvers, which not have a permanent connection and do not intersect with any operation. In the review [1], the authors detailed the main problems of BIM technologies use for infrastructural objects. With regard to the processes of operation, the situation is even more difficult, a transition from the schedule of the model ships to the planning of maritime spatial process is necessary for large marine ports. Accumulation of all the information that stores over the entire period from design to building construction into the final BIM model of the object (record BIM model) does not allow to form a separate model for operation. The creation of a separate information database, in which data is entered from the port dispatching service (time of entry and exit of the vessel, number of ship calls, time of loading and unloading, volume of cargo transshipment, working time budget, etc.) is necessary to carry out this. An important issue is the development of special techniques for the various risks [2] assessment at the port facility exploitation. Basics of planning of the building objects operation are standardized in $[3,4]$, however, their formalization and creation of standard templates as the pattern of a BIM standards of the enterprise or reference models and processes have not yet been carried out, there are only generalized and minimal requirements.

\section{Methods and materials}

2D construction documentation, designed as working drawings is available for most marine objects. We have analyzed at least 100 port mooring facilities, and only in rare cases, the project documentation and necessary calculations were available for them. The main document is the technical passport of the berth, which contains a minimum of information. The documentation composition is always heterogeneous and may differ for various constructions. If changes are made to a construction, then each engineer must redesign its design, which leads to a very inefficient, time-consuming and non-sequential process that is not standardized.

An important issue is the integration of geotechnical data [5] into the BIM model to improve and complement it. In most former projects, the information on ground is not taken into account that limits the information model. This is especially important in the Arctic regions, where the temperature regime of ground of the base must be stabilized, and constant differential monitoring of ground temperature should also be performed.

The integration methods of geotechnical data on geological structure into the information BIM model have not been sufficiently developed yet. For the objects of the marine transport infrastructure it is a critical disadvantage, since during the operation of the structures the main loads are directed to the grounds of base. In [6] we proposed equipment and techniques for deformation control of mooring walls of pile-anchored type. Indirectly, this can give an assessment of the ground state at pinching, but this technique is not standardized.

Additional problems are the lack of a library of standard building elements, part of the construction of mooring walls, fences or coast reinforcement are made of natural materials, torn stone, which are poorly visualized. For these elements, the LOD technology is difficult to formalize, the description of their structural links as the IFC model is also a difficult task. 
Figure 1 shows the 3D model of the berth developed by us, containing all the basic constructive elements for new building. However, its use for the facility operation is redundant, since the information model in such amount is not required. Since at the design stage each specialist independently develops and determines the constructive features of the facility, then, as a rule, he does not single out individual elements for subsequent operational monitoring of the technical condition.

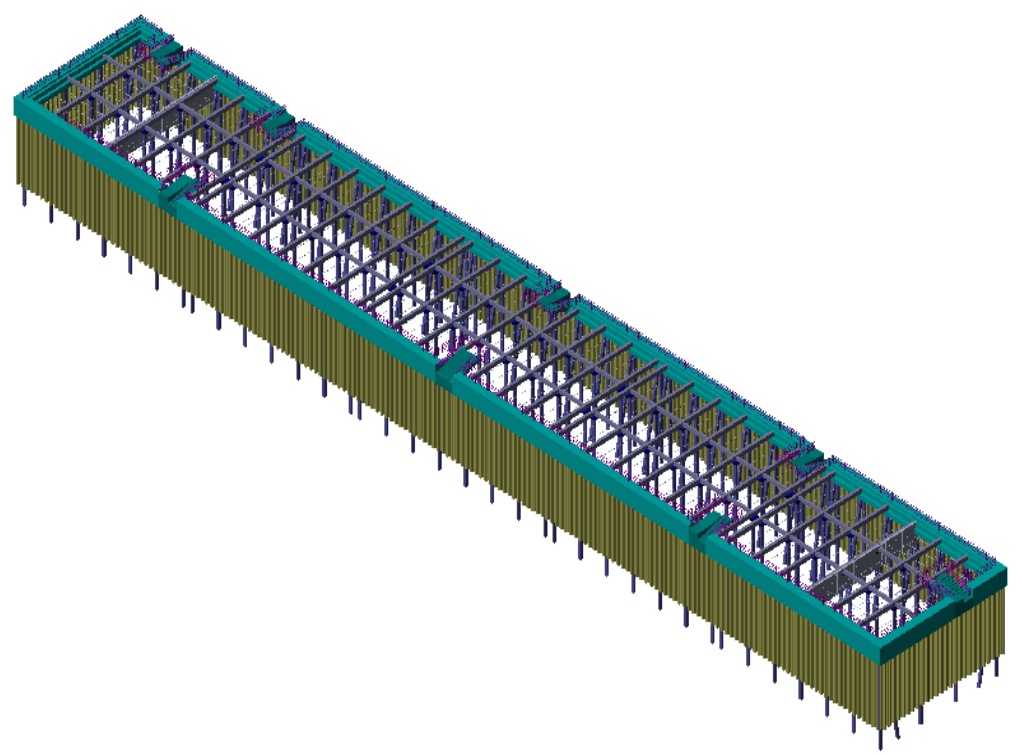

Fig. 1. The BIM model of the moorage sheet pile wall

In paper [7] the authors used the geographic information systems (GIS) for informative modeling of large-scale objects in the context of development projects of maritime transport infrastructure planning. That method also meets the individual requirements for construction of deformation geodetic network of extended marine building structures, for example, stone dam, coast reinforcement or an anchor-piles system. The implementation of geographic information systems will allow reconciling a full description of the wharf topography with main building constructive elements. This together defines the basic relationships between geometric objects of structures in different LOD systems of BIM model.

Thus, any changes in the berth structure will automatically update all dependent parameters at high and low levels of construction.

For example, on Figure 2 shows a 3D BIM model of the anchor assembly for the distributing belt of the mooring wall. For the tasks of exploitation and observation of the technical condition, it is of interest only to control the underwater side of the anchorage rods in the water, the assembly itself is visually unavailable, because this information will already be redundant. For GIS construction the assembly is a node of grid of anchor draft, its accurate position should be determined by the instrumental geodesic method. GIS tools allow automatic monitoring and determination of deviations in the network of deformations of a building structure and give recommendations in case of detection of dangerous movements. In this cooperation, the information BIM model, in first, automatically forms a geotechnical data array for the whole life cycle, and secondly organizes the correct exchange of data of various levels, from visual observations of the fastener safety to 
instrumental survey of the geodetic deformation network of the marine building mooring facility.

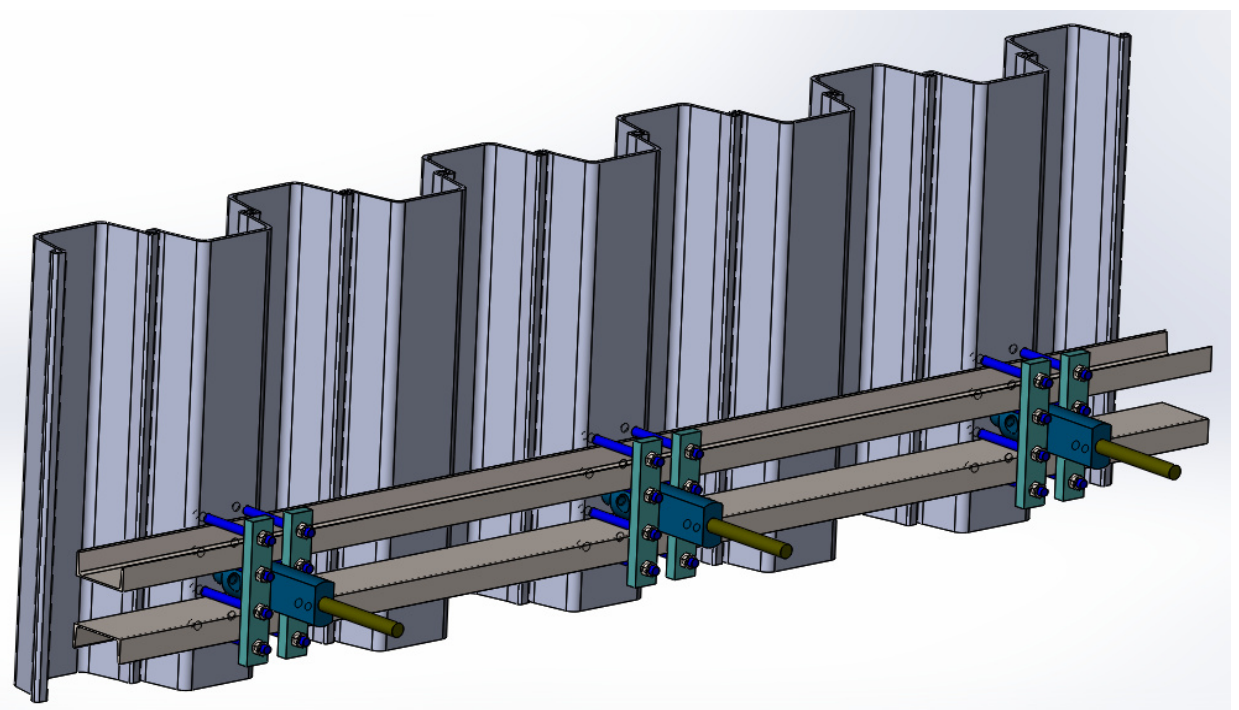

Fig. 2. The BIM model of the anchor assembly of the distributing belt with sheet pile wall

Similar data separation into some levels on standards within the BIM model composition was positively approved in [8] for transport infrastructure projects. The most detailed model of reinforcement of the concrete plate of base for the crane tracks of the seaport is presented in figure 3. Figure 4 shows a typical staircase descent on the pier, it was modeled from reinforced concrete, standard products for stair railings and ramps from existing libraries were also used. Such detail may be necessary for reconstruction projects or changes in the crane run, efforts calculation during free storage, etc. For seaports, where cargo operations are very intensive, the choice of places for the cargo crane installation and its movements is a very important task for information modeling. The rationale in the BIM model of tasks to optimize the crane installation, visualize its movement and coverage area are issues that are solved at the design stage yet [9]. For safe operation in work [10], the authors proposed to significantly expand the planning subject for the tower crane, reinforcing it by check on the basis of special rules and 4D simulations. 


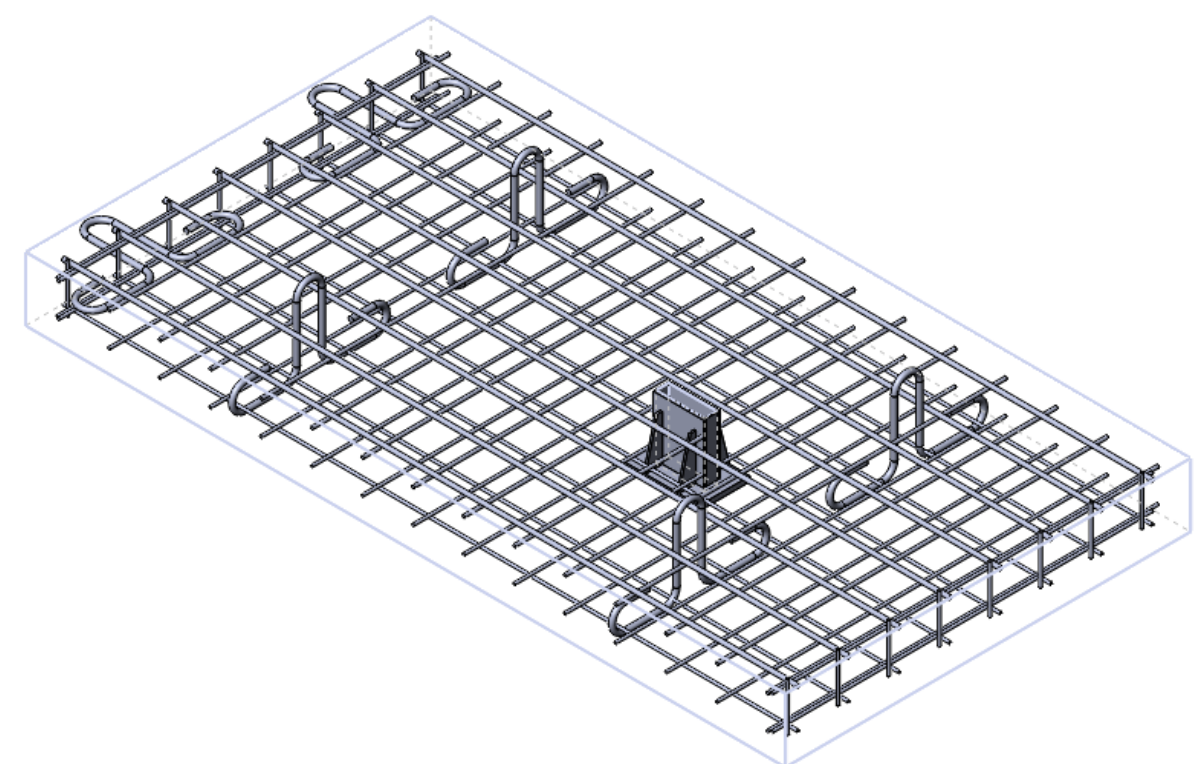

Fig. 3. The BIM model of the interchangeable reinforcement plate for the crane tracks and for storage of goods

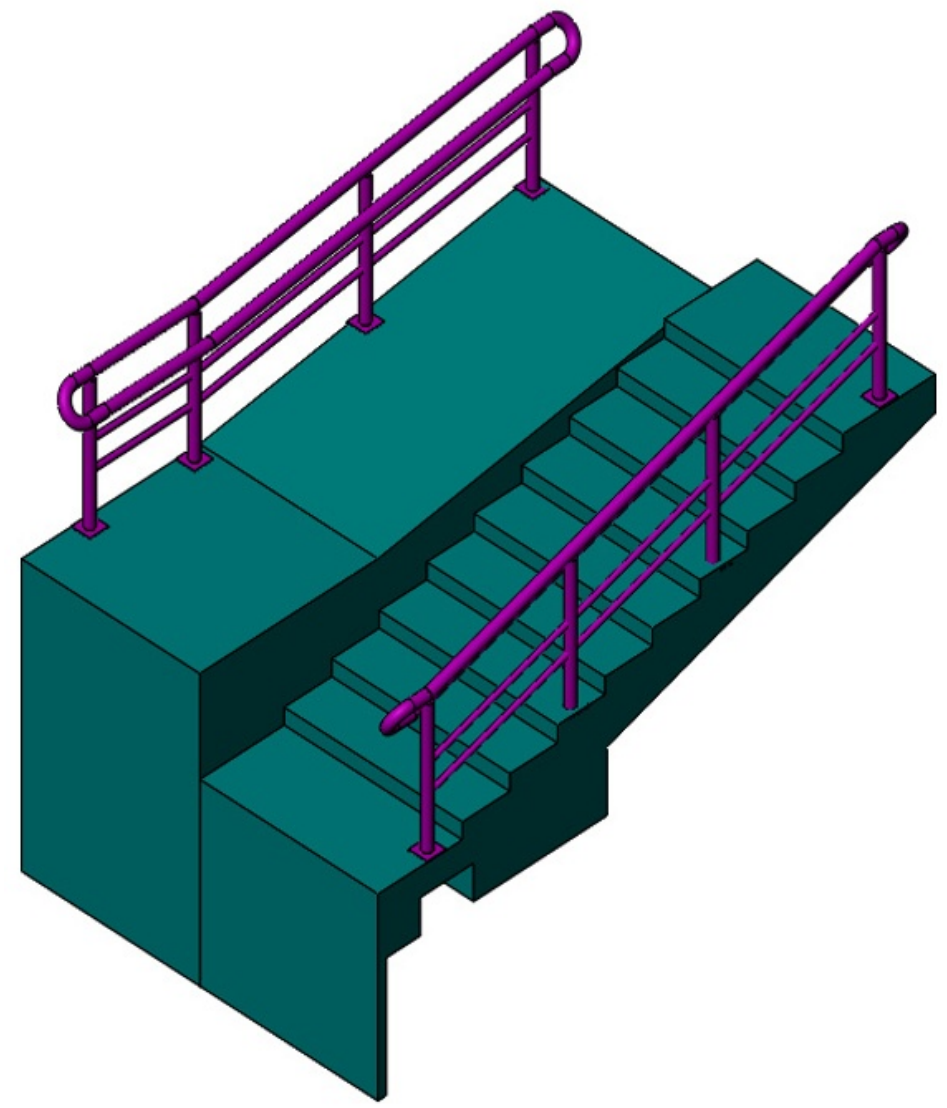

Fig. 4. The BIM model of a typical staircase on a pier 


\section{$3 \quad$ Results}

In general, the existing basic technologies of information modeling for maritime infrastructure facilities can be used to design only the building part. The additional solutions are required for development of the operational model of the mooring facility and the schedule formation of cargo operations. For example, a special soft for the management of visual assets [11], which combines for sharing the instrumental data, photographs and video sequences, can be such solution. This approach will significantly increase the quality of made decisions and the reliability of information. The next integrated solution is a special Management System [12], the core of which is a constant forecast of the technical state of the basic constructions through the use of the information BIM model. The authors offer to use Autodesk Dynamo Studio tools for data collection, and Microsoft Excel - for operational calculations.

Our proposals for creation of the working BIM model on the operation of marine port facilities are reduced to the scheme in figure 5, where the work process is presented. We do not provide a stage on the quay walls design, since in most cases the project documentation is not available and cannot be restored. All initial data are obtained from technical passports and executive documentation. We propose to use a ligament of Autodesk Revit and Microsoft Excel to build a framework. The main work on monitoring of the berths technical condition can be performed by both the operating organization and the test lab. The models for calculation of elements structural strength and risk assessment are performed by an expert organization.

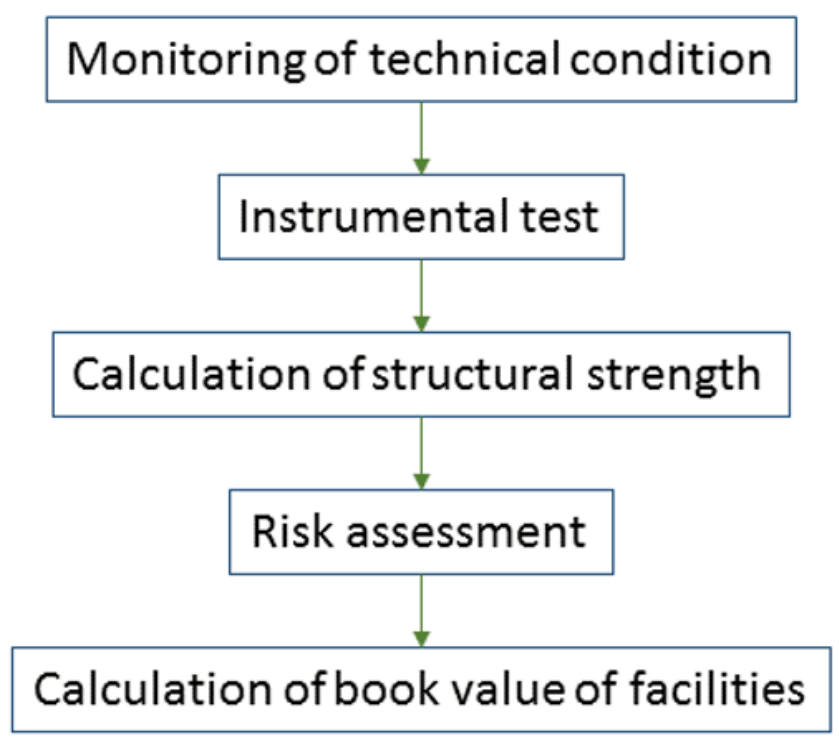

Fig. 5. Typical scheme of the monitoring of technical condition of marine quay wall

The information BIM model also provides the existence of work plans to maintain the facility in a good condition, instrumental and visual control, measures to assess the value of assets (book value). In [13] we proposed the basic principles of economic justification of costs at inspection of industrial safety, which can be used for predictive cost estimates of facilities service and the attraction of other resources. 


\section{Discussion}

For a full-fledged transition to information modeling (BIM) technologies as applied to water transport infrastructure facilities, coordination with a large number of federal ministries, agencies and other departments is required, which can only be worked out on real pilot projects that have been successfully completed. At present, there is no full-fledged classifier of building materials and products made according to a single standard. Existing databases of BIM components are heterogeneous, have a clear link to specific software, and do not have interoperability. There is no system for classifying and coding elements of marine building structures suitable for BIM, it can be built based on an information pricing system in building construction. Such a link will automatically generate budget documentation for any region, taking into account transport costs for the delivery of project cargo, determine the construction cost with maximum accuracy, a separate advantage is the ability to switch to life cycle contracts based on real data on the book value of the object without an interim cycle with assessment of fair value. In paper [14], an innovative facility management system is considered at the stage of design, operation and maintenance, taking into account the dynamic impacts of cargo movements using the infrastructure facility as a seaport during the processing of Panamax and PostPanamax type vessels. The combination of the principles of optimization of the construction part of the seaport and maximum productivity in the design based on information modeling provides the best opportunity to influence the life cycle of the structure as a whole. The authors in paper [15] consider options for using various standards and technical criteria in the design, construction and operation of offshore berthing facilities; this methodology facilitates the integration of object-oriented information modeling (BIM). In work [16] discusses the methodology for developing an alternative assessment of multimodal cargo terminals using most of the BIM digital tools. The logistic models are combined with various simulation models of cargo operations, as a result of which the life cycle calculation is more accurately performed at the project planning stage. In paper [17] proposed a model for assessing the complex effect of building a green port based on information on the construction of BIM. This model is intended for the intellectual analysis of information about the green building subject, taking into account the construction and subsequent integration of the green port.

\section{Conclusion}

At the design stage, it is necessary to allocate separate constructive elements for the subsequent monitoring of the technical conditions, the redundant data should not be included in the record BIM model, because this only complicates the operation process. The corporate BIM standard with sufficient accuracy should determine the processes of the formation of operational documentation obtained from different sources and enterprise departments. The schedules of maintenance and instrumental observations should be an integral part of the information BIM model.

Application of information modeling technologies for objects of maritime transport infrastructure and port structures solves the following tasks:

- The elimination of inconsistencies between all project participants in the areas of: research, design, organization of construction, construction, operation, maintenance, overhaul, disposal;

- The reduction of costs at the design and construction stage with subsequent benefits in operation;

- The clarification of the operating costs of the organization; 
- The ability to use relevant information about the structure without changes and distortions;

- The transition to life cycle contracts.

Herewith all the monitoring results of the technical condition should be formed in a single database, which will allow to assess the dynamics of deformation processes at all stages of the life cycle of the facility.

Additionally, the results of the study show that the reliability level of a comprehensive assessment of the green port construction effect when using the BIM model is high, and the reliability of the integrated green port construction assessment system is higher.

\section{References}

1. H. Bradley, R. Lark and S. Dunn, Automation in Construction 71(2) 139-152 (2016). DOI: 10.1016/j.autcon.2016.08.019

2. V. Sharmanov, T. Simankina and A. Mamaev, Construction of Unique Buildings and Structures 12(63) 113-124 (2017). DOI: 10.18720/CUBS.63.6

3. ISO 15686-1:2011 Buildings and constructed assets - Service life planning - Part 1: General principles and framework

4. BS 8536-1:2015 Briefing for design and construction. Code of practice for facilities management (Buildings infrastructure)

5. L.R. Tawelian and S.B. Mickovski, Procedia Engineering 143, 734-741 (2016). DOI:10.1016/j.proeng.2016.06.1151

6. P. Garibin and E. Ol'khovik, Proceedings of the International Conference on Port and Ocean Engineering under Arctic Conditions (POAC), 133185 (2017)

7. A. Borrmann, T.H. Kolbe, A. Donaubauer, H. Steuer, J.R. Jubierre and M. Flurl, Computer-Aided Civil and Infrastructure Engineering 30(4), 263-281 (2015)

8. M. Obergriesser and A. Borrmann, eWork and eBusiness in Architecture, Engineering and Construction, 581-587 (2012). DOI:10.1201/b12516-93

9. Y. Ji, B. Sankaran, J. Choi and F. Leite, Computing in Civil Engineering, 67-74 (2017). DOI: $10.1061 / 9780784480823.009$

10. Y. Ji and F. Leite, Automation in Construction [Internet] 93, 78-90 (2018). DOI: /10.1016/j.autcon.2018.05.003

11. M. Leon, D. Ahiaga-Dagbui, C. Fleming and R. Laing, Association of Researchers in Construction Management, ARCOM - 33rd Annual Conference, 765-774 (2017)

12. Dawood M 2017 BIM based bridge management system International Conference on Engineering, Project, and Product Management (Springer, Cham) p. 161-170

13. P. Garibin, E. Ol'khovik and I. Rastorguev, E3S Web of Conferences (EDP Sciences) 33 (2018). DOI:10.1051/e3sconf/20183303064

14. E. Ol'khovik, P.Garibin, and V. Tsuprik, Practice, Progress, and Proficiency in Sustainability, 338-369. (2019). DOI:10.4018/978-1-5225-6954-1.ch016.

15. P.Garibin, E. Ol'khovik, MATEC Web of Conferences 170, 03027 (2018). DOI:10.1051/matecconf $/ 201817003027$

16. P. Morales-Fusco, E. Martín, G. Soley, 3-rd Interdisciplinary Conference on Production, Logistics and Traffic (ICPLT) (2017)

17. M. Cao, X. Duan, X. Zhao, Journal of Coastal Research, 93(1), 1073 (2019)/ DOI:10.2112/si93-155.1 